\title{
Article
}

\section{Family-led rehabilitation after stroke in India (ATTEND): a randomised controlled trial}

Lindley, R. I, Anderson, C.S., Billot, L., Forster, A., Hackett, Maree, Harvey, L.A., Jan, S., Li, Q., Liu, H. and Et, Al

Available at http://clok.uclan.ac.uk/35735/

Lindley, R. I, Anderson, C.S., Billot, L., Forster, A., Hackett, Maree ORCID: 0000-0003-1211-9087, Harvey, L.A., Jan, S., Li, Q., Liu, H. et al (2017) Familyled rehabilitation after stroke in India (ATTEND): a randomised controlled trial. The Lancet, 390 (10094). pp. 588-599. ISSN 0140-6736

It is advisable to refer to the publisher's version if you intend to cite from the work. http://dx.doi.org/10.1016/S0140-6736(17)31447-2

For more information about UCLan's research in this area go to http://www.uclan.ac.uk/researchgroups/ and search for <name of research Group>.

For information about Research generally at UCLan please go to http://www.uclan.ac.uk/research/

All outputs in CLoK are protected by Intellectual Property Rights law, including Copyright law. Copyright, IPR and Moral Rights for the works on this site are retained by the individual authors and/or other copyright owners. Terms and conditions for use of this material are defined in the policies page.

\section{CLoK}

Central Lancashire online Knowledge www.clok.uclan.ac.uk

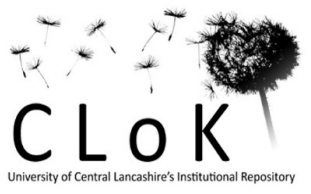


Family-led rehabilitation after stroke in India: a randomised controlled trial

ATTEND Collaborative Group*

\section{Writing Committee}

Professor Richard I Lindley MD

The George Institute for Global Health

Sydney Medical School - Westmead Hospital, Discipline of Medicine

Westmead Hospital (C24)

University of Sydney

Sydney, NSW 2006

Australia

$+61298455082$

Richard.lindley@sydney.edu.au

Professor Craig S Anderson PhD

The George Institute for Global Health

Royal Prince Alfred Hospital and University of Sydney

PO Box M201

Missenden Road, Camperdown

Sydney, NSW 2050

Australia

canderson@georgeinstitute.org.au 
Associate Professor Laurent Billot MRes

Sydney Medical School, University of Sydney

The George Institute for Global Health

PO Box M201

Missenden Road, Camperdown

Sydney, NSW 2050

Australia

lbillot@georgeinstitute.org

Professor Anne Forster PhD

Leeds Institute of Health Sciences

University of Leeds

Leeds, West Yorkshire, UK LS2 9JT

A.Forster@leeds.ac.uk

Associate Professor Maree L Hackett PhD

The George Institute for Global Health

PO Box M201

Missenden Road, Camperdown

Sydney, NSW 2050

Australia

mhackett@georgeinstitute.org.au

Professor Lisa A Harvey PhD 
University of Sydney

Sydney, NSW, AUS 2006

Lisa.harvey@sydney.edu.au

Professor Stephen Jan PhD

The George Institute for Global Health

University of Sydney

PO Box M201

Missenden Road, Camperdown

Sydney, NSW 2050

Australia

sjan@georgeinstitute.org

Mr Qiang Li Mbiostat

The George Institute for Global Health

PO Box M201

Missenden Road, Camperdown

Sydney, NSW 2050

Australia

qli@georgeinstitute.org

Dr Hueiming Liu MB BS 
The George Institute for Global Health

PO Box M201

Missenden Road, Camperdown

Sydney, NSW 2050

Australia

hliu@georgeinstitute.org.au

Professor Peter Langhorne PhD

Institute of Cardiovascular and Medical Sciences

University of Glasgow

Glasgow, UK G31 2ER

peter.langhorne@glasgow.ac.uk

Dr Pallab K Maulik PhD

The George Institute for Global Health India

Delhi, India 110025

pmaulik@georgeinstitute.org.in

Professor Gudlavalleti Venkata Satyanarayana Murthy MD

Indian Institute of Public Health

Hyderabad, India 500033

murthy.gvs@iiphh.org 
Professor Marion F Walker PhD

University of Nottingham

Nottingham, Nottinghamshire, UK NG7 2UH

Marion.Walker@nottingham.ac.uk

Professor Jeyaraj D Pandian DM

Christian Medical College and Hospital Ludhiana

Ludhiana, Punjab, India 141008

jeyarajpandian@hotmail.com

\section{Corresponding author}

Professor Richard I Lindley

The George Institute for Global Health

University of Sydney

PO Box M201

Missenden Rd

Camperdown

NSW 2050

Australia

Tel +61 298455082 
Fax +61298459731

rlindley@georgeinstitute.org.au

richard.lindley@sydney.edu.au 


\section{Abstract}

Background: Most people with stroke in India have no access to organised rehabilitation services. The effectiveness of training family members to provide stroke rehabilitation is uncertain. Our primary objective was to determine whether family-led stroke rehabilitation, initiated in hospital and continued at home, would be superior to usual care, in a low resource setting.

Methods: The Family-led Rehabilitation after Stroke in India (ATTEND) trial was a prospectively randomised open trial with blinded endpoints (PROBE) conducted across 14 hospitals in India. Patients (and their caregivers) were randomised to intervention or usual care by site coordinators, using a secure web-based system, with minimisation by site and stroke severity. The intervention group received additional structured rehabilitation training, commenced in hospital and continued at home for up to 2 months. The primary outcome was death or dependency, defined by scores 3 to 6 on the modified Rankin scale (range, 0 [no symptoms] to 6 [death]) as assessed by blinded observers at six months. Secondary outcomes included any serious adverse event, hospital length of stay, activities of daily living, health-related quality of life, anxiety and depression, and caregiver strain. All analyses were intention to treat.

Registration: Clinical Trials Registry-India (CTRI/2013/04/003557); Australian New Zealand Clinical Trials Registry (ACTRN12613000078752); and Universal Trial Number (U1111-1138-6707)

Findings: A total of 1,250 patients were randomised (623 intervention and 627 control) between 13 January 2014 and 12 February 2016. At six months, 285 of 607 $(47 \cdot 0 \%)$ participants in the intervention group were dead or dependent compared to 287 of $605(47 \cdot 4 \%)$ in the control group (odds ratio $0 \cdot 98 ; 95 \%$ confidence Interval 
$0 \cdot 78$ to $1 \cdot 23, P=0 \cdot 87)$. No significant differences were observed in any of the secondary or safety outcomes .

Interpretation: Family-led rehabilitation did not improve outcome after stroke unit admission.

Funding: The National Health and Medical Research Council of Australia Abstract word count $307(\max 300)$ 


\section{Family-led rehabilitation after stroke in India: A Randomised Controlled Trial}

Stroke rates are rising in low- and middle-income countries (LMIC) but services are limited. ${ }^{1}$ Task shifting rehabilitation activities to unpaid caregivers may offer a sustainable alternative to conventional rehabilitation, and provide an affordable strategy in meeting the health demands in high and LMICs. ${ }^{2-5}$ India, with one sixth of the world's population, only has approximately 35 stroke units, located mainly in urban centres. ${ }^{6,7}$ Consequently most people have no access to specialised stroke care and little access to conventional rehabilitation programs. Given that LMICs only have about $3 \%$ equivalent purchasing power to spend on healthcare compared to high-income countries, any new model of stroke rehabilitation should be both sustainable and effective..$^{8,9}$ Our hypothesis was that family caregiver delivered rehabilitation would increase independence and survival after stroke unit admission. We report the results of the Family-led Rehabilitation after Stroke in India (ATTEND) trial, which evaluated a rehabilitation training program to deliver family-led rehabilitation after stroke.

\section{Methods}

Study design

ATTEND was a prospectively randomised open trial with blinded endpoint (PROBE) conducted across 14 hospitals in India. Approvals were obtained from the ethics committees of the University of Sydney, Australia and at each participating hospital. Permission was also obtained from the Health Ministry Screening Committee, New Delhi. The protocol was published prior to unblinding. ${ }^{10}$

Participants 
Patients were eligible if they had an informal family or other caregiver who was willing to deliver rehabilitation, were aged 18 years or older, had a stroke within the past month, were able to be randomised within 7 days of admission to hospital, had residual disability (defined by needing help from another person for everyday activities) had a reasonable expectation of survival (i.e. not for palliative care, no evidence of widespread cancer), and would be available for follow-up for 6 months, and they and their caregiver provided consent. Site Coordinators screened all admitted stroke patients and obtained written informed consent from patients and caregivers.

\section{Randomisation and masking}

The trial funded full-time Stroke Coordinators (physiotherapists) and blinded assessors at each site. The stroke coordinator assessed patients for eligibility, consented them, and collected key baseline and demographic data prior to randomisation. The stroke coordinator was also responsible for training the patients and caregivers. Patients were randomised (1:1) to intervention or a usual care control group via a secure web-based central randomisation system with minimisation by site and stroke severity (National Institutes of Health Stroke Scale [NIHSS] scores $<8$ versus $\geq 8$ ). To address potential unblinding Stroke Coordinators were not permitted to treat other non-trial stroke patients or share an office with the blinded assessor. Coordinators were instructed to conduct training sessions in a private room or behind curtains. Assessors were kept unaware of the details of the trial intervention, including having separate training sessions at annual collaborator meetings. Any inadvertent unblinding at an assessment was recorded.

\section{Procedures}


The family rehabilitation training intervention was delivered in addition to routine rehabilitation at each site. An international steering group developed the culturally specific intervention, piloted an early version, ${ }^{11}$ and incorporated features to ensure it could be affordable when scaled up. The intervention was designed to be delivered by a rehabilitation professional (coordinator), commenced in hospital and continued at home. It involved training family members to provide a simplified version of evidence-based rehabilitation, ${ }^{12-14}$ and included: comprehensive impairment and disability assessment by the coordinators; information provision; joint goal setting with the patient and caregiver for basic activities of daily living (ADL), extended activities of daily living (EADL), communication; caregiver training for limb positioning; encouragement of the practice of task-specific activities; and reminders to prepare the patient and carer for hospital discharge. After hospital discharge, the coordinator performed up to six home visits to assess progress, continue caregiver training activities and reset goals. The training was designed to occur for approximately one hour a day in hospital, for about three days, with the intention of expediting early supported discharge. ${ }^{10}$ There was a written intervention guide for the coordinators and an intervention manual for the patient and caregiver. To reduce potential contamination, the manual was given to participants on the first home visit to prevent access by control participants in hospital. ${ }^{11}$ In our trial sites, usual care consisted of some therapy during hospital stay, with post-discharge care varying from no therapy to limited out-patient therapy sessions.

To ensure intervention fidelity across sites, coordinators were collectively trained at study initiation and annual collaborator meetings, supplemented by on-site training as required. Intervention training was led by physiotherapists from India and 
Australia. Day-to-day support was provided by a clinical coordination team that included a neurologist and physiotherapist. A log of trial interventions was collected by the Stroke Coordinator for each participant for hospital and home visit activities. Intervention patients (with their caregivers) were encourage by the Stroke Coordinator to keep a daily log of rehabilitation activities for 30 days after discharge.

Only the steering and management committee members and coordinators were aware of the details of the family rehabilitation training intervention (including the written guide).

\section{Outcomes}

The primary outcome was the proportion of patients who were dead or disabled at six months as defined by scores of 3-6 on the modified Rankin scale (mRS) The $\mathrm{mRS}$ is a global seven-level measure of functioning with scores of 0 to 2 representing good outcome and functional independence, 3 to 5 representing increasing levels of disability, and 6 death. ${ }^{15}$ Events during the initial hospital stay were collected by the unblinded coordinators: all other outcomes, including the primary outcome, were assessed by trained blinded assessors who evaluated the patient and caregiver at home, or at the hospital, or by phone if a face-to-face visit was not possible. A secondary outcome was an ordinal 'shift' analysis of the full range of categories of the $\mathrm{mRS}$. Other outcomes included the simple validated recovery and dependency questions, ${ }^{16}$ length of hospital stay, place of residence (whether the same as before stroke, Yes/No), the Barthel Index (BI) of ADL (on a scale of 0 to 100 with lower scores representing fewer activities), ${ }^{17}$ the Nottingham 
EADL scale (on a scale of 0 to 66 with lower scores representing fewer activities), ${ }^{18}$ quality of life measured by the World Health Organisation Quality of Life (WHOQOLBREF, with domains scored from 0 to 100 with lower scores representing lower quality of life) ${ }^{19}$ and the EuroQol Group 5-Dimension Self-Report Questionnaire (EQ5D) which includes an overall health state (on a scale of 0 to 100 , with lower scores representing lower quality of life), ${ }^{20}$ and patient anxiety and depression according to the Hospital Anxiety and Depression Scale subscales (HADS, with lower scores indicating fewer symptoms). ${ }^{21}$ Caregiver outcomes were the Caregiver Burden Scale (on a scale from 21 to 84 , with lower scores representing less burden) and anxiety and depression on the HADS subscales. ${ }^{22}$ Adverse events, including a pre-specified list of those most frequent after stroke, were sought. These included deaths due to: the initial stroke; myocardial infarction; pneumonia; other vascular or non-vascular. Our pre-specified non-fatal events were: recurrent stroke; myocardial infarction; bony fracture; infection; or other. All outcomes were also assessed at 3 months. Patients and caregivers were given a health diary to record details of any re-hospitalisation, with details collected at each assessment.

Statistical analysis

Based on the Early Supported Discharge Stroke trials, ${ }^{13}$ where death or disability was $50 \%$ in controls, a sample size of 1,200 (600 per group) was estimated to provide $90 \%$ power (a 0.05$)$ to detect a $21 \%$ relative risk reduction $(10.5 \%$ absolute reduction) in death or disability in the intervention group with a $20 \%$ loss to follow-up.

All analyses were according to the intention-to-treat principle, and all tests were twosided with a nominal level of significance of $5 \%$. The primary analysis compared the 
proportion of patients who were dead or dependent (mRS 3 to 6 ) at 6 months between the intervention and usual care groups in an unadjusted logistic regression model. Sensitivity analyses included adjustment for study site, stroke severity, age, sex, household income and patient level of education. Eight pre-specified subgroup analyses (age, stroke severity, stroke pathology, stroke Oxfordshire Community Stroke Project Classification, carer type, education level, household income and type of accommodation were performed by adding the subgroup variable as well as its interaction term, with the intervention as fixed effects to the logistic regression model used for the primary analysis. Sex had been inadvertently omitted (due to author error) in the statistical analysis plan and is also included for completeness. ${ }^{23}$ Other analyses included all 7 categories of the mRS using ordinal logistic regression and a permutation test proposed by Howard et al. ${ }^{24}$ Analyses of secondary outcomes at 3 and 6 months used t-tests to compare means (e.g. mean BI score) and chi-square tests to compare proportions (e.g. place of residence). Length of hospital stay was analysed using a log-rank test and serious adverse events using Fisher's Exact test. Further details are available in the Statistical Analysis Plan which was finalised and submitted for publication before unblinding. ${ }^{25}$ All analyses were conducted using SAS Enterprise Guide version 7·1 (SAS/Stat version 9-4). An independent Data and Safety Management Committee monitored the unblinded accumulating results and adverse events according to a written charter.

The trial was registered at the Clinical Trials Registry-India (CTRI/2013/04/003557); the Australian New Zealand Clinical Trials Registry (ACTRN12613000078752); and has a Universal Trial Number (U1111-1138-6707).

Trial Management 
The trial was funded by the National Health and Medical Research Council of Australia with overall management of the study coordinated from The George Institute for Global Health, Sydney, Australia. Weekly teleconferences were undertaken between study personnel in Sydney and India during the preparation, conduct, and close-out of the trial. The national clinical coordination centre was based in Ludhiana, Punjab, India and project management was based at The George Institute India, Hyderabad, Telangana, India. The Indian Institute of Public Health, Hyderabad, Telangana provided independent trial monitoring. Additional logic checks and central monitoring of data were performed. The trial methods were piloted in Ludhiana ${ }^{11}$ and the protocol was published. ${ }^{10}$ The steering committee designed the study, collected the data (in collaboration with the hospital sites), made the decision to submit the manuscript for publication and vouch for the fidelity of the study to the protocol. The writing committee wrote the manuscript and vouch for the completeness and accuracy of the data and analyses. The George Institute for Global Health was responsible for analysis of the data.

\section{Role of the funding source}

The National Health and Medical Research Council had no role in study design, data collection, data analysis, data interpretation, or writing of the report. The corresponding author had full access to all the data in the study and had final responsibility for the decision to submit for publication.

\section{Results}

A total of 1,250 participants were randomised between 13 January 2014 and 12 February 2016. The flow of participants is shown in Figure 1. Baseline characteristics 
are shown in Table 1. At hospital discharge there was no difference in mRS scores between intervention and control (90.4\% dead or dependent in both, $\mathrm{P}=0.96)$, nor of the $\mathrm{BI}(43.0$ in intervention, 43.2 in control, $\mathrm{P}=0.88)$ (Table $1 \mathrm{~S}$ ).

The training program was delivered as planned with a mean (standard deviation) time of $3.0(1.6)$ hours (median 2.9) in hospital. An additional 3.1 (1.7) hours (median $2 \cdot 8$ ) of training was delivered during home visits. Intervention patients and caregivers reported $17 \cdot 8$ hours $(21 \cdot 6)$ of rehabilitation performed in the first 30 days following hospital discharge (data available from 574 participants). Details of the rehabilitation provided to both groups as part of routine care, and the intervention are shown in Table 2S. There was no evidence of a difference in total routine hospital rehabilitation time $(2 \cdot 0$ hours for intervention, $2 \cdot 1$ hours for control patients, $P=0 \cdot 23)$, although intervention participants practised fewer mobility activities than control participants $(83 \cdot 6 \%$ intervention versus $88 \cdot 2 \%$ control, $\mathrm{P}=0 \cdot 023)$. There were no statistical differences in other non-trial routine rehabilitation activities (Table 2S).

At six months $285 / 607(47 \cdot 0 \%)$ participants were dead or disabled in the intervention group compared to $287 / 605(47 \cdot 4 \%)$ in the control group, odds ratio $0.98(95 \%$ confidence interval $[\mathrm{Cl}] 0 \cdot 78$ to $1 \cdot 23, \mathrm{P}=0.87$ ) (Table 3 ). The neutral results were similar in adjusted analyses and across all secondary outcomes (Tables 3 and 4, Table 2S). The mean (SD) number of days from randomisation to hospital discharge was $6.0(6 \cdot 8)$ in the intervention group and $6 \cdot 3(7 \cdot 5)$ in the control group $(P=0.65)$. The intervention did not reduce total length of stay (mean [SD] stay of $9 \cdot 3$ [7-4] days in the intervention group versus $9 \cdot 5[7 \cdot 9]$ days for control $(P=0 \cdot 58)$ (Table 1S). There were no significant differences in non-fatal or fatal adverse events (Table 5), 
with $72(11 \cdot 9 \%)$ deaths in the intervention group compared with $86(14 \cdot 2 \%)$ in the control $(P=0 \cdot 23)$. In the intervention group, there were 9 deaths due to the initial stroke and 18 in controls $(P=0.08)$. There was no between group difference in caregiver strain, nor in anxiety or depression on the HADS. We documented unblinding in $5.3 \%$ of intervention patients and $3 \cdot 3 \%$ of control patients $(P=0.09)$.

There was one significant interaction on the pre-specified subgroup analysis, by sex, where there were reduced odds of death or dependency in men at six months (odds ratio $0.83,95 \% \mathrm{Cl} 0.63$ to 1.10 versus odds ratio $1.39,95 \% \mathrm{Cl} 0.93$ to 2.05 for women, $\mathrm{P}=0.04$ for interaction) (Figure 2).

\section{Discussion}

Our study showed that the addition of family-led rehabilitation training to usual stroke unit care did not decrease death or disability at six months, nor was there any benefit noted at the three-month assessment. In addition, the training did not influence any of the other physical, emotional or quality of life outcomes. The intervention was safe, with an observed non-significant reduction in deaths, and no increase in caregiver burden. The training was delivered as planned with a mean of $3 \cdot 0$ (median $2 \cdot 9$ ) hours of hospital training and a mean of $3 \cdot 1$ hours (median $2 \cdot 8$ ) of communitybased training, with components consistent with the trial intervention guide. In the context of these Indian stroke units, where patients only received a total of two hours of therapy, the intervention more than doubled the amount of hospital rehabilitation and provided additional community caregiver and patient training. In the intervention group, 30 minutes of daily reported rehabilitation activities were reported by the patient and caregivers in the month after discharge. 
The ATTEND intervention failed to decrease hospital length of stay. When our results are viewed in the context of the systematic review of early supported discharge after stroke ${ }^{13}$ (see Research in context), it can be seen that interventions without coordination from a dedicated multidisciplinary team currently lack evidence of benefit. We also note that the recently reported smaller RECOVER trial of nursedelivered rehabilitation after stroke in China was negative ( $R$ Lindley, personal communication).

Our results are also consistent with the lack of benefit seen in a recent systematic review of trials of caregiver-mediated exercises to improve activities of daily living. ${ }^{26}$ In this overview, the authors noted that there were few data (only 333 patients included in the six trials analysed), and that the quality of evidence was low- to moderate. Whilst the ATTEND intervention emphasised caregiver-mediated exercises, these were not the only component of the intervention.

The lack of benefit of the family-rehabilitation intervention has important implications for stroke recovery research, behavioural change, and task shifting in general. Our training program may not have been sufficient (in time and content) to deliver effective family rehabilitation, as we only observed about 30 minutes of daily activities in the intervention group. Conventional western rehabilitation is usually associated with greater daily therapy time (1-2 hours) ${ }^{27}$ The training of family members was designed to be sustainable, and if family members required more training to meet the needs of their family patient, then the aspiration of routinely 
providing rehabilitation through task shifting to family caregivers may not be feasible. Family dynamics may also limit the effectiveness of this strategy, and task shifting to a non-family generic health worker, such as the established Indian Accredited Social Health Activist (ASHA), may have been a more effective strategy, although likely more expensive. Technology assisted rehabilitation may also be another option of "task-shifting" that is the subject of current trials. ${ }^{28}$

The lack of benefit may also have been due to individual training components being ineffective in changing behaviour. This possibility was raised by another trial, undertaken in the United Kingdom, where caregiver training (part of our intervention) was ineffective in the acute setting. ${ }^{29}$ As we were aware of these results before commencing our study, emphasis was also placed on the importance of continuing caregiver training after hospital discharge. The comprehensive nature of our intervention may have diluted the impact of individual components, and this lack of focus, for example, too much time spent on information provision, may have been at the expense of training task-specific mobility exercises.

Although our primary outcome was not significant, the sample size may still have been insufficient to detect a more modest treatment effect. However, the consistency of results across all health dimensions provides support for the overall neutral effect. The main qualitative differences between conventional rehabilitation in high income countries, compared to our family rehabilitation intervention, are in the professional multidisciplinary structure and frequent review meetings. Our results suggest that the lower dose of family rehabilitation training, delivered by a single professional, whilst based upon evidence-based components across multiple disciplines, is an ineffective 
model of care. Given our trial was performed at stroke units around India, our findings have not ruled out the possibility that the intervention could offer benefits in non-specialised hospitals, especially in rural and remote settings.

The unexpected interaction with sex, with the observed improved outcome in men compared with women, may be due to the play of chance and requires further analysis. However, in Indian society, there may be important sex differences in the receipt and provision of a complex intervention such as ours. Our process evaluation aims to explore this, and other aspects of the trial, in more detail. ${ }^{30}$

Strengths of our study include the piloting and development of a structured intervention supported by written materials and use of robust trial methods to address priorities set out in the WHOMorld Bank World Report on Disability. ${ }^{9}$ Our funding provided sufficient resources to address the research question comprehensively and has contributed to building stroke research capacity across India. Our trial data are consistent with epidemiological evidence that stroke is affecting people in India about 15 years younger than those in high-income countries, highlighting the public health importance of improving global rehabilitation services, especially given that many of our participants were still working. ${ }^{31}$ However, there are limitations given that our participants were generally from urban centres with higher than average education and income, thus potentially limiting the generalisability of these results to other areas of the country without any rehabilitation. 
Task shifting is an attractive solution for healthcare sustainability. ${ }_{4}^{4,32,33}$ However, in none of 22 recommendations of the WHO Task Shifting Guidelines was there reference to evidence generation on effectiveness, despite acknowledgement their implementation should be accompanied by rigorous evaluation. ${ }^{4}$ Our evaluation of training the patient and family caregiver showed that this particular model of rehabilitation was ineffective. Our results illustrate that task shifting away from conventional rehabilitation, without rigorous evaluation, could waste limited resources. Our neutral results will be further interrogated through a process evaluation which will examine the social and economic influences on the behaviour of carers and patients. In addition, our results suggest that future research in this area should incorporate more behavioural change theory and evidence, when developing a new intervention. However, ATTEND was developed from the evidence base current at the time and focused on pragmatic practical solutions.

In summary, our trial of family-led stroke rehabilitation was ineffective at improving health outcomes across a wide variety of dimensions. Alternative models of care to improve stroke recovery are required, especially those for the populations of LMICs where the burden of stroke is enormous.

Main text word count 3565

\section{Panel: Research in context}

In low and middle income countries, community rehabilitation is seen as a high priority for health care delivery to reduce disability. Systematic reviews of early supported discharge (ESD) stroke services have shown this model of care reduces 
death or dependency without adverse effects on family caregivers. We updated the search strategy (to January 2017) for the Cochrane review of ESD services (services for reducing the duration of hospital care for acute stroke patients) that categorises interventions into those with or without coordinated multidisciplinary team input. We identified two similar RCTs $(n=289)$ in the latter category that tested a similar intervention; ATTEND pilot study; and an unpublished Chinese trial of nursedelivered rehabilitation after stroke.

Added value of this study

This is the first large RCT to test task shifting of stroke rehabilitation to family members. This approach did not improve outcome (compared to usual care) after stroke unit admission. The results were consistent with previous smaller RCTs of ESD services without multidisciplinary team coordination.

Implications of all the available evidence Family-led rehabilitation does not improve outcomes, but did not increase harms such as increased burden of care for the family. These results do not support investing in new stroke rehabilitation services that shift tasks to family caregivers. Future models of low-cost stroke rehabilitation should investigate task shifting to non-family workers or team based community care. 


\section{Legends}

Figure 1: Trial profile

\section{Table 1: Baseline characteristics}

Notes for Table 1

Data are $\mathrm{N}(\%)$ unless indicated otherwise

*Data complete for sex and age, One patient withdrew after randomization and denominator is 622 for other baseline variables in the intervention group

† INR Household income in Indian rupees (INR) per month

USA $\$ 1=68 I N R$

‡ OCSP: Oxfordshire Community Stroke Project Stroke Classification for those with ischaemic stroke

$\S$ NIHSS: National Institutes of Health Stroke Scale

|| Percentage only shown as denominator varies due to missing data

\section{Table 2: Analysis of mRS}

Notes for Table 3

* Sensitivity analyses included adjustment for study site, stroke severity, age, sex, household income and patient level of education. The P-value from the likelihood ratio test of the logistic regression

$\dagger$ Adjusted analysis includes the following covariates: study site, stroke severity (NIHSS Score $<8$ or $>=8$ ), age (as a continuous variable), sex, income $(<5000$, $5000-<15000,15000-<30000,30000$ and more, no answer/missing) and education (college/university/postgraduate, high school, primary/secondary/less than primary school, no schooling/missing)

‡ Primary outcome 
$\S$ Ordinal analysis performed using proportional odds logistic regression

Figure 3

Patients achieving each mRS score at 6 months

$\mathrm{mRS}=$ modified Rankin Scale

Table 3: Analysis of secondary outcomes at Month 3 and Month 6

Table 4 Notes

* P-value by Chi-square test

† P-value by Chi-square test only performed on "same as before stroke" versus

"other"

‡ P-value by t-test

Figure 3: Main subgroup analyses

${ }^{*}$ NIHSS: National Institutes of Health Stroke Scale

†OCSP: Oxfordshire Community Stroke Project Stroke Classification

‡Level of education for patient

§Household income in Indian rupees (INR) per month

USA $\$ 1=68 \mathrm{INR}$

Table 1S: Hospital discharge information

Table 1S Notes

* P-value by Log-rank test

† P-value by t-testT

$\ddagger$ P-value by Chi-square test 


\section{Table 2S: Routine and intervention therapy}

Notes for Table 2S

* P-value by t-test

† Total number of sessions

‡ Number and proportion of patients with at least one activity

$\S$ P-value by Fisher's exact test

Table 3S: Distribution of categories on the modified Rankin scale (mRS) between intervention and control using the assumption-free statistical method of Howard

Table 3S Notes

*Howard G, Waller JL, Voeks JH, et al. A simple, assumption-free, and clinical interpretable approach for analysis of modified Rankin outcomes. Stroke 2012;43:664-669.

The assumption-free approach considers all possible pairs of observations where the first observation is taken from the Intervention group (YT) and the second observation is taken from the Control group YC. If group YT included $n$ observations and group included $m$ observations, the two-group comparison would lead to the total of $n \times m$ pairs of observations. In each pair, the observation from the treatment group will either be worse than the control observation, the same as the control observation, or better than the control observation. The probabilities that in a randomly chosen pair of treatment and control patients, the treatment patients has worse outcome (Prob $(Y T>Y C))$, the same outcome $(\operatorname{Prob}(Y T+Y C))$ or better outcome $(\operatorname{Prob}(Y T<Y C))$, can then be estimated as the ratio of the number of pairs satisfying each of these individual conditions to the total number of $\mathrm{n} \times \mathrm{m}$ pairs.

The permutation test first calculates a 'test statistic' for the observed data. In our study, we tested how far the observed proportion of non-tied pairs was from the null-hypothesis of $50 \%$. The permutation test randomly assigned treatments to individuals, ensuring no association between treatment and the test statistic (guaranteeing the null hypothesis is true). This process was repeated 10,000 times, and the distribution of the test statistic under the null hypothesis was estimated. Whether the observed test statistic is unusual under the null hypothesis (that is, the P value) is simply the location of the observed test statistic in distribution of test statistics under the null hypothesis.

Table 4S Safety outcomes 
Table 4S Notes

* Fisher's exact test comparing the proportion of patients with at least one event

† Total number of events (one patient can contribute more than one event)

Contributions

JDP originally suggested the study. JDP, RIL, CSA, LB, AF, MLH, LAH, SJ, PL, PKM, GVSM, MFW designed the study and obtained funding. QL and LB did the statistical analysis. HL led the Process Evaluation. RIL wrote the first draft of the manuscript and all writing committee members contributed, edited and approved the final version. 


\section{Figure 1}

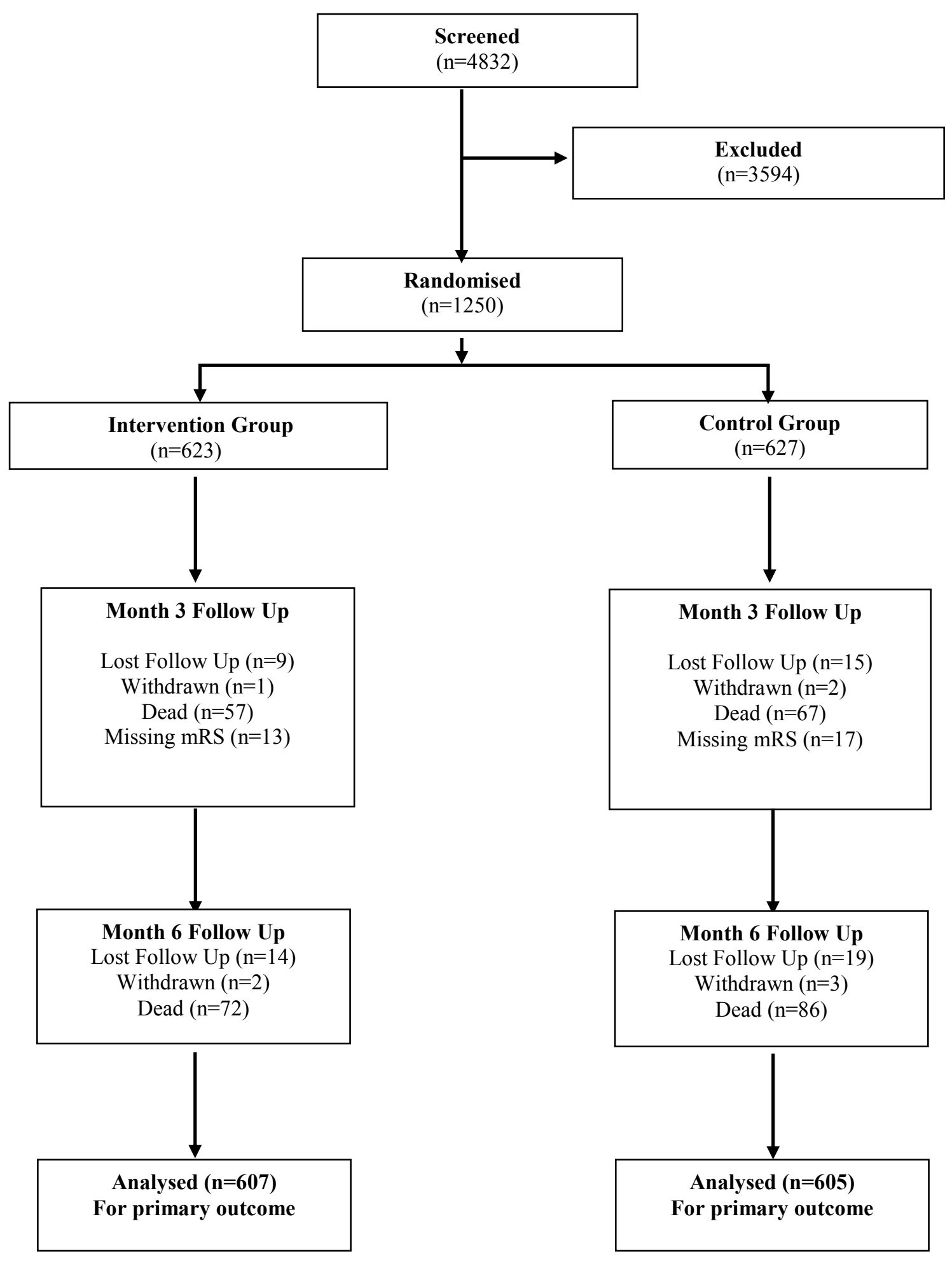


Table 1: Baseline characteristics

\begin{tabular}{lccc}
\hline & Intervention & Control & Total \\
Socio-demographic characteristics & $\mathbf{( N = 6 2 3 )}$ & $\mathbf{( N = 6 2 7 )}$ & $\mathbf{( N = 1 2 5 0 )}$ \\
\hline Sex & & & $837(67 \cdot 0 \%)$ \\
Male & $421(67 \cdot 6 \%)$ & $416(66 \cdot 3 \%)$ & $413(33 \cdot 0 \%)$ \\
Female & $202(32 \cdot 4 \%)$ & $211(33 \cdot 7 \%)$ &
\end{tabular}

\section{Age (years)}

$\mathrm{N}$ Mean (SD)

Median (interquartile range)

$\min \max$

$18-<40$

$40-<50$

$50-<60$

$60-<70$

$70-<80$

$>=80$

\section{Marital status*}

Married

Unmarried

Separated

Widowed

\section{Main caregiver}

Spouse

Mother

Father

Grandfather and Others

Daughter / Daughter in law

Son / Son in law

$\begin{array}{ccc}62357 \cdot 5(12 \cdot 92) & 62758 \cdot 0(14 \cdot 21) & 125057 \cdot 7(13 \cdot 58) \\ 58(50 \text { to } 66) & 59(49 \text { to } 67) & 59(50 \text { to } 66) \\ 1895 & 1995 & 1895 \\ 58(9 \cdot 3 \%) & 63(10 \cdot 0 \%) & 121(9 \cdot 7 \%) \\ 89(14 \cdot 3 \%) & 97(15 \cdot 5 \%) & 186(14 \cdot 9 \%) \\ 189(30 \cdot 3 \%) & 159(25 \cdot 4 \%) & 348(27 \cdot 8 \%) \\ 175(28 \cdot 1 \%) & 176(28 \cdot 1 \%) & 351(28 \cdot 1 \%) \\ 89(14 \cdot 3 \%) & 89(14 \cdot 2 \%) & 178(14 \cdot 2 \%) \\ 23(3 \cdot 7 \%) & 43(6 \cdot 9 \%) & 66(5 \cdot 3 \%)\end{array}$




\begin{tabular}{lccc}
\hline & Intervention & Control & Total \\
Socio-demographic characteristics & $\mathbf{( N = 6 2 3 )}$ & $\mathbf{( N = 6 2 7 )}$ & $\mathbf{( N = 1 2 5 0 )}$ \\
\hline Sister & $3(0 \cdot 5 \%)$ & $8(1 \cdot 3 \%)$ & $11(0 \cdot 9 \%)$ \\
Brother & $17(2 \cdot 7 \%)$ & $19(3 \cdot 0 \%)$ & $36(2 \cdot 9 \%)$ \\
Hired Help / nurse & $4(0.6 \%)$ & $3(0 \cdot 5 \%)$ & $7(0.6 \%)$
\end{tabular}

\section{Highest level of education completed (patient)}

$\begin{array}{lccr}\text { No schooling } & 88(14 \cdot 1 \%) & 96(15 \cdot 3 \%) & 184(14 \cdot 7 \%) \\ \text { Less than primary school } & 58(9 \cdot 3 \%) & 65(10 \cdot 4 \%) & 123(9 \cdot 8 \%) \\ \text { Primary school completed } & 113(18 \cdot 2 \%) & 106(16 \cdot 9 \%) & 219(17 \cdot 5 \%) \\ \text { Secondary school completed } & 68(10 \cdot 9 \%) & 57(9 \cdot 1 \%) & 125(10 \cdot 0 \%) \\ \text { High school completed } & 123(19 \cdot 8 \%) & 142(22 \cdot 6 \%) & 265(21 \cdot 2 \%) \\ \text { College/university completed } & 142(22 \cdot 8 \%) & 140(22 \cdot 3 \%) & 282(22 \cdot 6 \%) \\ \text { Postgraduate degree } & 29(4 \cdot 7 \%) & 21(3 \cdot 3 \%) & 50(4 \cdot 0 \%) \\ \text { Unknown } & 1(0 \cdot 2 \%) & 0(0 \cdot 0 \%) & 1(0 \cdot 1 \%)\end{array}$

\section{Work status (patient)}

$\begin{array}{lccc}\text { Management } & 4(0 \cdot 6 \%) & 7(1 \cdot 1 \%) & 11(0 \cdot 9 \%) \\ \text { Professional and related } & 22(3 \cdot 5 \%) & 19(3 \cdot 0 \%) & 41(3 \cdot 3 \%) \\ \text { Service } & 85(13 \cdot 7 \%) & 75(12 \cdot 0 \%) & 160(12 \cdot 8 \%) \\ \text { Sales / Commercial } & 64(10 \cdot 3 \%) & 57(9 \cdot 1 \%) & 121(9 \cdot 7 \%) \\ \text { Construction } & 27(4 \cdot 3 \%) & 29(4 \cdot 6 \%) & 56(4 \cdot 5 \%) \\ \text { Armed Forces } & 7(1 \cdot 1 \%) & 9(1 \cdot 4 \%) & 16(1 \cdot 3 \%) \\ \text { Farming/ forestry/ fishing and related } & 60(9 \cdot 6 \%) & 65(10 \cdot 4 \%) & 125(10 \cdot 0 \%) \\ \text { Clerical/ administrative support } & 21(3 \cdot 4 \%) & 14(2 \cdot 2 \%) & 35(2 \cdot 8 \%) \\ \text { Installation and related } & 8(1 \cdot 3 \%) & 4(0 \cdot 6 \%) & 12(1 \cdot 0 \%) \\ \text { Manufacture/ production } & 16(2 \cdot 6 \%) & 21(3 \cdot 3 \%) & 37(3 \cdot 0 \%) \\ \text { Transportation/ driver } & 25(4 \cdot 0 \%) & 27(4 \cdot 3 \%) & 52(4 \cdot 2 \%) \\ \text { Housewife } & 181(29 \cdot 1 \%) & 186(29 \cdot 7 \%) & 367(29 \cdot 4 \%) \\ \text { Not Applicable } & 102(16 \cdot 4 \%) & 114(18 \cdot 2 \%) & 216(17 \cdot 3 \%)\end{array}$

\section{Work situation (patient)}




\begin{tabular}{lccc}
\hline & Intervention & Control & Total \\
Socio-demographic characteristics & $\mathbf{( N = 6 2 3 )}$ & $\mathbf{( N = 6 2 7 )}$ & $\mathbf{( N = 1 2 5 0 )}$ \\
\hline Part time paid work & $46(7 \cdot 4 \%)$ & $50(8 \cdot 0 \%)$ & $96(7 \cdot 7 \%)$ \\
Retired & $96(15 \cdot 4 \%)$ & $111(17 \cdot 7 \%)$ & $207(16 \cdot 6 \%)$ \\
Unemployed & $47(7 \cdot 6 \%)$ & $31(4 \cdot 9 \%)$ & $78(6 \cdot 2 \%)$ \\
Home duties & $171(27 \cdot 5 \%)$ & $203(32 \cdot 4 \%)$ & $374(29 \cdot 9 \%)$ \\
Student & $3(0 \cdot 5 \%)$ & $3(0 \cdot 5 \%)$ & $6(0 \cdot 5 \%)$ \\
Others & $35(5 \cdot 6 \%)$ & $43(6 \cdot 9 \%)$ & $78(6 \cdot 2 \%)$
\end{tabular}

\section{Accommodation details}

$\begin{array}{lccc}\text { Own house } & 501(80 \cdot 5 \%) & 498(79 \cdot 4 \%) & 999(80 \cdot 0 \%) \\ \text { Own apartment/ flat } & 19(3 \cdot 1 \%) & 26(4 \cdot 1 \%) & 45(3 \cdot 6 \%) \\ \text { Rented flat } & 37(5 \cdot 9 \%) & 36(5 \cdot 7 \%) & 73(5 \cdot 8 \%) \\ \text { Rented accommodation in a house } & 42(6 \cdot 8 \%) & 47(7 \cdot 5 \%) & 89(7 \cdot 1 \%) \\ \text { Government/ company provided house } & 22(3 \cdot 5 \%) & 17(2 \cdot 7 \%) & 39(3 \cdot 1 \%) \\ \text { Jhuggi (slum) } & 0(0 \cdot 0 \%) & 1(0 \cdot 2 \%) & 1(0 \cdot 1 \%) \\ \text { Others } & 1(0 \cdot 2 \%) & 2(0 \cdot 3 \%) & 3(0 \cdot 2 \%)\end{array}$

\section{Living situation pre-stroke}

$\begin{array}{lccc}\text { Independent at home } & 616(99 \cdot 0 \%) & 610(97 \cdot 3 \%) & 1226(98 \cdot 2 \%) \\ \text { Dependent at home } & 6(1 \cdot 0 \%) & 12(1 \cdot 9 \%) & 18(1 \cdot 4 \%) \\ \text { Others } & 0(0 \cdot 0 \%) & 5(0 \cdot 8 \%) & 5(0 \cdot 4 \%)\end{array}$

\section{Financial situation}

Patient / his close family owns the house

Patient / his close family owns the flat

Rented from landlord

Government owned / allocated housing

$\begin{array}{ccc}507(81 \cdot 5 \%) & 508(81 \cdot 0 \%) & 1015(81 \cdot 3 \%) \\ 18(2 \cdot 9 \%) & 20(3 \cdot 2 \%) & 38(3 \cdot 0 \%) \\ 77(12 \cdot 4 \%) & 83(13 \cdot 2 \%) & 160(12 \cdot 8 \%) \\ 20(3 \cdot 2 \%) & 16(2 \cdot 6 \%) & 36(2 \cdot 9 \%)\end{array}$

\section{Monthly Household income (INR) †}

$\begin{array}{lllr}<5000 & 93(15 \cdot 0 \%) & 101(16 \cdot 1 \%) & 194(15 \cdot 5 \%) \\ 5000-14,999 & 178(28 \cdot 6 \%) & 196(31 \cdot 3 \%) & 374(29 \cdot 9 \%) \\ 15,000-29,999 & 166(26 \cdot 7 \%) & 151(24 \cdot 1 \%) & 317(25 \cdot 4 \%)\end{array}$




\begin{tabular}{lccc}
\hline & Intervention & Control & Total \\
Socio-demographic characteristics & $\mathbf{( N = 6 2 3 )}$ & $\mathbf{( N = 6 2 7 )}$ & $\mathbf{( N = 1 2 5 0 )}$ \\
\hline $30,000-59,999$ & $99(15 \cdot 9 \%)$ & $74(11 \cdot 8 \%)$ & $173(13 \cdot 9 \%)$ \\
$60,000-100,000$ & $18(2 \cdot 9 \%)$ & $20(3 \cdot 2 \%)$ & $38 /(3 \cdot 0 \%)$ \\
More than 100,000 & $8(1 \cdot 3 \%)$ & $12(1 \cdot 9 \%)$ & $20(1 \cdot 6 \%)$ \\
Decline to answer & $39(6 \cdot 3 \%)$ & $43(6 \cdot 9 \%)$ & $82(6 \cdot 6 \%)$ \\
Don't know & $21(3 \cdot 4 \%)$ & $30(4 \cdot 8 \%)$ & $51(4 \cdot 1 \%)$
\end{tabular}

\section{Time from stroke onset to randomisation (days)}

\begin{tabular}{|c|c|c|c|}
\hline $\mathrm{N}$ Mean (SD) & $6234.9(3 \cdot 8)$ & $6275 \cdot 1(4 \cdot 1)$ & $12505 \cdot 0(4 \cdot 1)$ \\
\hline Median (interquartile range) & 4 (3 to 6$)$ & $4(2$ to 6$)$ & 4 (3 to 6$)$ \\
\hline
\end{tabular}

\section{Stroke type}

$\begin{array}{lccr}\text { Ischaemic } & 478(76 \cdot 8 \%) & 478(76 \cdot 2 \%) & 956(76 \cdot 5 \%) \\ \text { Large artery atherosclerosis } & 214(44 \cdot 8 \%) & 213(44 \cdot 7 \%) & 427(44 \cdot 7 \%) \\ \text { Cardio embolism } & 75(15 \cdot 7 \%) & 54(11 \cdot 3 \%) & 129(13 \cdot 5 \%) \\ \text { Small artery occlusion } & 113(23 \cdot 6 \%) & 131(27 \cdot 5 \%) & 244(25 \cdot 5 \%) \\ \text { Determined, other etiology } & 16(3 \cdot 3 \%) & 21(4 \cdot 4 \%) & 37(3 \cdot 9 \%) \\ \text { Undetermined } & 60(12 \cdot 6 \%) & 58(12 \cdot 2 \%) & 118(12 \cdot 4 \%) \\ \text { Intracerebral haemorrhage } & 143(23 \cdot 0 \%) & 148(23 \cdot 6 \%) & 291(23 \cdot 3 \%) \\ \text { Unspecified } & 1(0 \cdot 2 \%) & 1(0 \cdot 2 \%) & 2(0 \cdot 2 \%)\end{array}$

\section{OCSP classification $\ddagger$}

Total anterior circulation syndrome

Partial anterior circulation syndrome

Posterior circulation syndrome

Lacunar syndromes

$\begin{array}{lll}67(14 \cdot 0 \%) & 51(10 \cdot 7 \%) & 118(12 \cdot 4 \%) \\ 263(55 \cdot 0 \%) & 269(56 \cdot 4 \%) & 532(55 \cdot 7 \%) \\ 72(15 \cdot 1 \%) & 76(15 \cdot 9 \%) & 148(15 \cdot 5 \%) \\ 76(15 \cdot 9 \%) & 81(17 \cdot 0 \%) & 157(16 \cdot 4 \%)\end{array}$

\section{NIHSS score $\S$}

N Mean (SD)

Median (interquartile range)

$\begin{array}{crr}62210 \cdot 1(4 \cdot 9) & 6279 \cdot 6(4 \cdot 8) & 12499 \cdot 9(4 \cdot 9) \\ 9(6 \text { to } 13) & 9(6 \text { to } 12) & 9(6 \text { to } 13)\end{array}$




\begin{tabular}{|c|c|c|c|}
\hline Socio-demographic characteristics & $\begin{array}{l}\text { Intervention } \\
\qquad(\mathrm{N}=623)\end{array}$ & $\begin{array}{l}\text { Control } \\
(\mathrm{N}=627)\end{array}$ & $\begin{array}{c}\text { Total } \\
(\mathrm{N}=1250)\end{array}$ \\
\hline $\min \max$ & 129 & 128 & 129 \\
\hline $0-<5$ & $72(11 \cdot 6)$ & $103(16 \cdot 4)$ & $175(14 \cdot 0)$ \\
\hline $5-<10$ & $247(39 \cdot 7)$ & $241(38 \cdot 4)$ & $488(39 \cdot 1)$ \\
\hline $10-<15$ & $188(30 \cdot 2)$ & $182(29 \cdot 0)$ & $370(29 \cdot 6)$ \\
\hline$>=15$ & $115(18 \cdot 5)$ & $101(16 \cdot 1)$ & $216(17 \cdot 3)$ \\
\hline \multicolumn{4}{|l|}{ Medical history $\|$} \\
\hline Hypertension & $73 \cdot 6 \%$ & $74 \cdot 2 \%$ & $73 \cdot 9 \%$ \\
\hline Diabetes Mellitus & $44 \cdot 7 \%$ & $43 \cdot 2 \%$ & $43 \cdot 9 \%$ \\
\hline Dyslipidaemia & $22 \cdot 2 \%$ & $24 \cdot 6 \%$ & $23 \cdot 4 \%$ \\
\hline Atrial fibrillation & $7 \cdot 9 \%$ & $7 \cdot 5 \%$ & $7 \cdot 7 \%$ \\
\hline Coronary artery disease & $15 \cdot 6 \%$ & $16 \cdot 2 \%$ & $15 \cdot 9 \%$ \\
\hline Obesity & $15 \cdot 3 \%$ & $15 \cdot 6 \%$ & $15 \cdot 5 \%$ \\
\hline Smoking & $25 \cdot 6 \%$ & $23 \cdot 0 \%$ & $24 \cdot 3 \%$ \\
\hline Alcohol use & $26 \cdot 5 \%$ & $27 \cdot 2 \%$ & $26 \cdot 8 \%$ \\
\hline Drug addiction & $0 \cdot 6 \%$ & $0 \cdot 2 \%$ & $0 \cdot 4 \%$ \\
\hline Carotid stenosis & $19 \cdot 9 \%$ & $18 \cdot 5 \%$ & $19 \cdot 2 \%$ \\
\hline Previous stroke/TIA & $17 \cdot 9 \%$ & $18 \cdot 2 \%$ & $18 \cdot 0 \%$ \\
\hline Rheumatic heart disease & $3 \cdot 4 \%$ & $3 \cdot 6 \%$ & $3.5 \%$ \\
\hline Neoplastic disease & $0.5 \%$ & $0.6 \%$ & $0.6 \%$ \\
\hline Pregnancy & $0.0 \%$ & $0 \cdot 3 \%$ & $0 \cdot 2 \%$ \\
\hline
\end{tabular}




\section{Table 2: Analysis of mRS}

\begin{tabular}{|c|c|c|c|c|c|c|c|}
\hline Outcome & $\begin{array}{l}\text { Intervention } \\
\qquad \begin{array}{c}(\mathrm{N}=623) \\
\text { n/N (\%) }\end{array}\end{array}$ & $\begin{array}{l}\text { Usual care } \\
\qquad \begin{array}{l}\text { (N=627) } \\
\text { n/N (\%) }\end{array}\end{array}$ & $\begin{array}{c}\text { Total } \\
(\mathrm{N}=1250) \\
\text { n/N (\%) }\end{array}$ & $\begin{array}{l}\text { Odds } \\
\text { Ratio }\end{array}$ & & $\begin{array}{l}\qquad 5 \% \\
\text { Confidence intervals }\end{array}$ & p-value* \\
\hline \multicolumn{8}{|l|}{ Primary outcome } \\
\hline \multicolumn{8}{|c|}{ Death or disability (mRS score 3 to 6 ) } \\
\hline Month 6 (Unadjusted) $\ddagger$ & $285 / 607(47 \cdot 0)$ & $287 / 605(47 \cdot 4)$ & $572 / 1212(47 \cdot 2)$ & 0.98 & $0 \cdot 78$ & $1 \cdot 23$ & $0 \cdot 87$ \\
\hline \multicolumn{8}{|c|}{ Death or disability (mRS score 3 to 6 ) } \\
\hline Month 3 (Unadjusted) & $336 / 600(56 \cdot 0)$ & $337 / 593(56 \cdot 8)$ & $673 / 1193(56 \cdot 4)$ & 0.97 & $0 \cdot 77$ & $1 \cdot 22$ & $0 \cdot 77$ \\
\hline Month 3 (Adjusted) † & $335 / 599(55 \cdot 9)$ & $337 / 593(56 \cdot 8)$ & $672 / 1192(56 \cdot 4)$ & $1 \cdot 00$ & $0 \cdot 77$ & $1 \cdot 29$ & 0.99 \\
\hline Month 6 (Adjusted) & $284 / 606(46 \cdot 9)$ & $287 / 605(47 \cdot 4)$ & $571 / 1211(47 \cdot 2)$ & $1 \cdot 02$ & $0 \cdot 80$ & $1 \cdot 31$ & $0 \cdot 87$ \\
\hline \multicolumn{8}{|l|}{ Ordinal analysis§ } \\
\hline \multicolumn{8}{|l|}{ Month 3 (Unadjusted) } \\
\hline 0 & $23 / 600(3 \cdot 8)$ & $27 / 593(4 \cdot 6)$ & $50 / 1193(4 \cdot 2)$ & 0.92 & $0 \cdot 75$ & $1 \cdot 12$ & $0 \cdot 42$ \\
\hline 1 & $147 / 600(24 \cdot 5)$ & 130/ $593(21 \cdot 9)$ & $277 / 1193(23 \cdot 2)$ & & & & \\
\hline 2 & $94 / 600(15 \cdot 7)$ & $99 / 593(16 \cdot 7)$ & $193 / 1193(16 \cdot 2)$ & & & & \\
\hline 3 & $141 / 600(23 \cdot 5)$ & $133 / 593(22 \cdot 4)$ & $274 / 1193(23 \cdot 0)$ & & & & \\
\hline
\end{tabular}




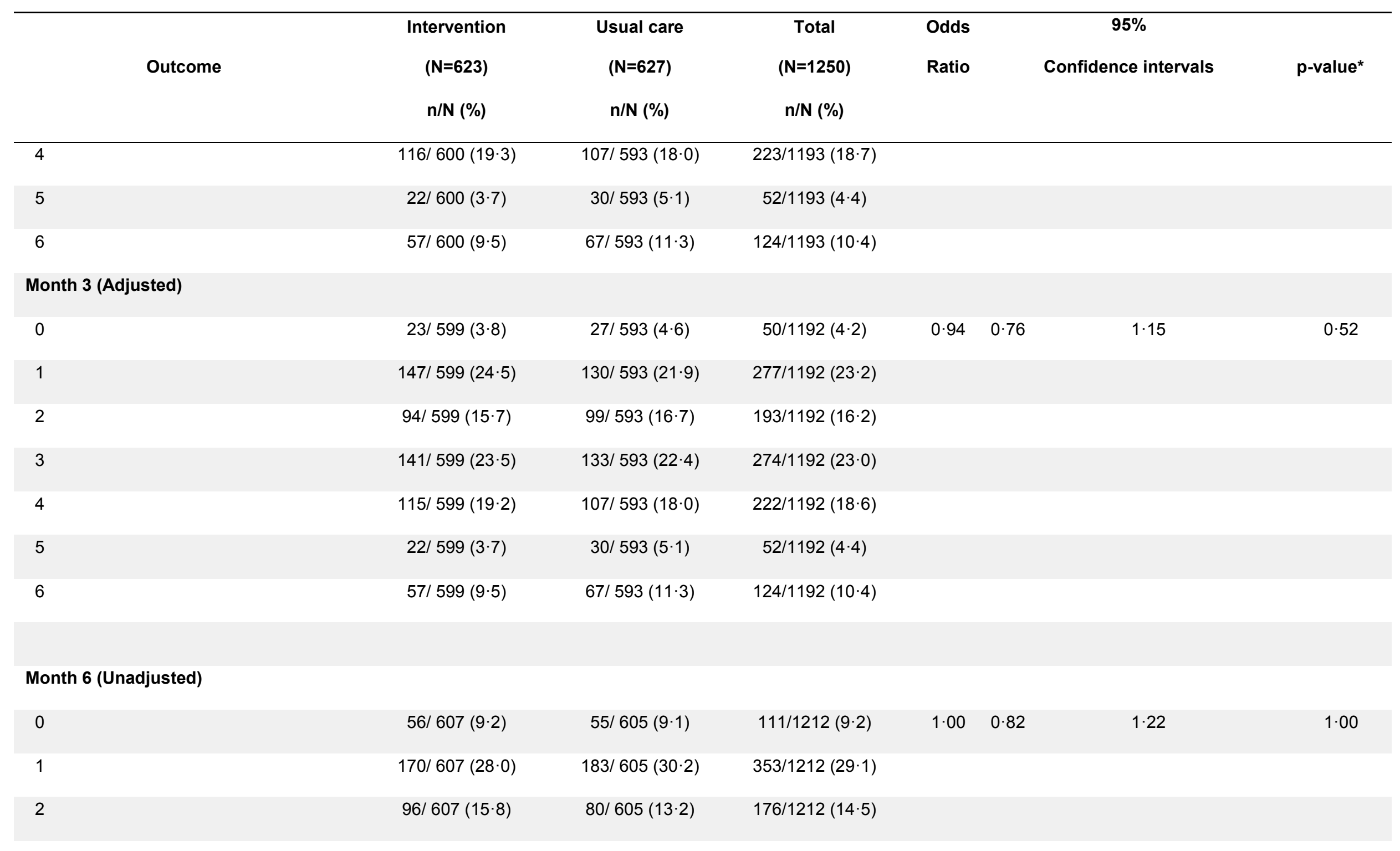




\begin{tabular}{|c|c|c|c|c|c|c|c|}
\hline \multirow[t]{2}{*}{ Outcome } & $\begin{array}{l}\text { Intervention } \\
\qquad(\mathrm{N}=623)\end{array}$ & $\begin{array}{l}\text { Usual care } \\
\qquad(\mathrm{N}=627)\end{array}$ & $\begin{array}{c}\text { Total } \\
(\mathrm{N}=1250)\end{array}$ & $\begin{array}{l}\text { Odds } \\
\text { Ratio }\end{array}$ & & $\begin{array}{l}\qquad 95 \% \\
\text { Confidence intervals }\end{array}$ & p-value* \\
\hline & n/N (\%) & n/N (\%) & n/N (\%) & & & & \\
\hline 3 & $120 / 607(19 \cdot 8)$ & $123 / 605(20 \cdot 3)$ & $243 / 1212(20 \cdot 0)$ & & & & \\
\hline 4 & $82 / 607(13 \cdot 5)$ & $65 / 605(10 \cdot 7)$ & $147 / 1212(12 \cdot 1)$ & & & & \\
\hline 5 & $11 / 607(1 \cdot 8)$ & $13 / 605(2 \cdot 1)$ & $24 / 1212(2 \cdot 0)$ & & & & \\
\hline 6 & $72 / 607$ (11.9) & $86 / 605(14 \cdot 2)$ & $158 / 1212(13 \cdot 0)$ & & & & \\
\hline \multicolumn{8}{|l|}{ Month 6 (Adjusted) } \\
\hline 0 & $56 / 606(9 \cdot 2)$ & $55 / 605(9 \cdot 1)$ & $111 / 1211(9 \cdot 2)$ & $1 \cdot 03$ & $0 \cdot 84$ & $1 \cdot 27$ & $0 \cdot 75$ \\
\hline 1 & $170 / 606(28 \cdot 1)$ & $183 / 605(30 \cdot 2)$ & $353 / 1211(29 \cdot 1)$ & & & & \\
\hline 2 & $96 / 606(15 \cdot 8)$ & $80 / 605(13 \cdot 2)$ & $176 / 1211(14 \cdot 5)$ & & & & \\
\hline 3 & $120 / 606(19 \cdot 8)$ & $123 / 605(20 \cdot 3)$ & $243 / 1211(20 \cdot 1)$ & & & & \\
\hline 4 & $81 / 606(13 \cdot 4)$ & $65 / 605(10 \cdot 7)$ & $146 / 1211(12 \cdot 1)$ & & & & \\
\hline 5 & $11 / 606(1 \cdot 8)$ & $13 / 605(2 \cdot 1)$ & $24 / 1211(2 \cdot 0)$ & & & & \\
\hline 6 & $72 / 606$ (11.9) & $86 / 605(14 \cdot 2)$ & $158 / 1211(13 \cdot 0)$ & & & & \\
\hline
\end{tabular}

\section{Sensitivity analysis for month $6^{*}$}

Death or disability

Month 6 (Unadjusted)

Month 6 (Adjusted)
$292 / 615(47 \cdot 5)$
$291 / 614(47 \cdot 4)$

291/ $611(47 \cdot 6)$

$583 / 1226(47 \cdot 6)$

$582 / 1225(47 \cdot 5)$

$0.99 \quad 0.79$

$1 \cdot 24$

$1 \cdot 31$ 


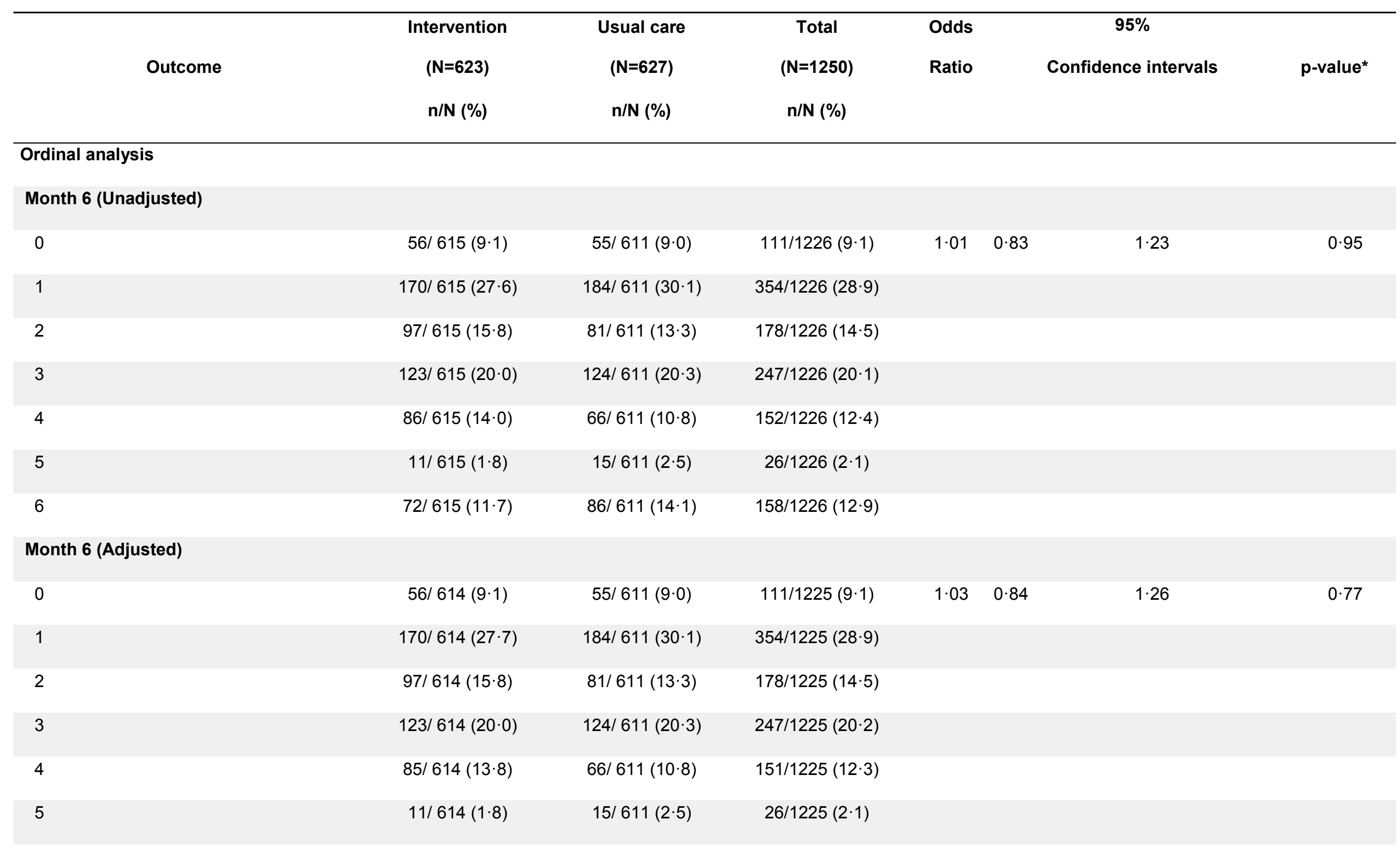




\begin{tabular}{|c|c|c|c|c|c|c|}
\hline Outcome & $\begin{array}{l}\text { Intervention } \\
\qquad(\mathrm{N}=623)\end{array}$ & $\begin{array}{l}\text { Usual care } \\
(\mathrm{N}=627)\end{array}$ & $\begin{array}{c}\text { Total } \\
(\mathrm{N}=1250)\end{array}$ & $\begin{array}{l}\text { Odds } \\
\text { Ratio }\end{array}$ & $\begin{array}{c}95 \% \\
\text { Confidence intervals }\end{array}$ & p-value* \\
\hline & n/N (\%) & n/N (\%) & n/N (\%) & & & \\
\hline 6 & $72 / 614(11 \cdot 7)$ & $86 / 611(14 \cdot 1)$ & $158 / 1225(12 \cdot 9)$ & & & \\
\hline
\end{tabular}


Figure 2: Primary outcome of $\mathrm{mRS}$

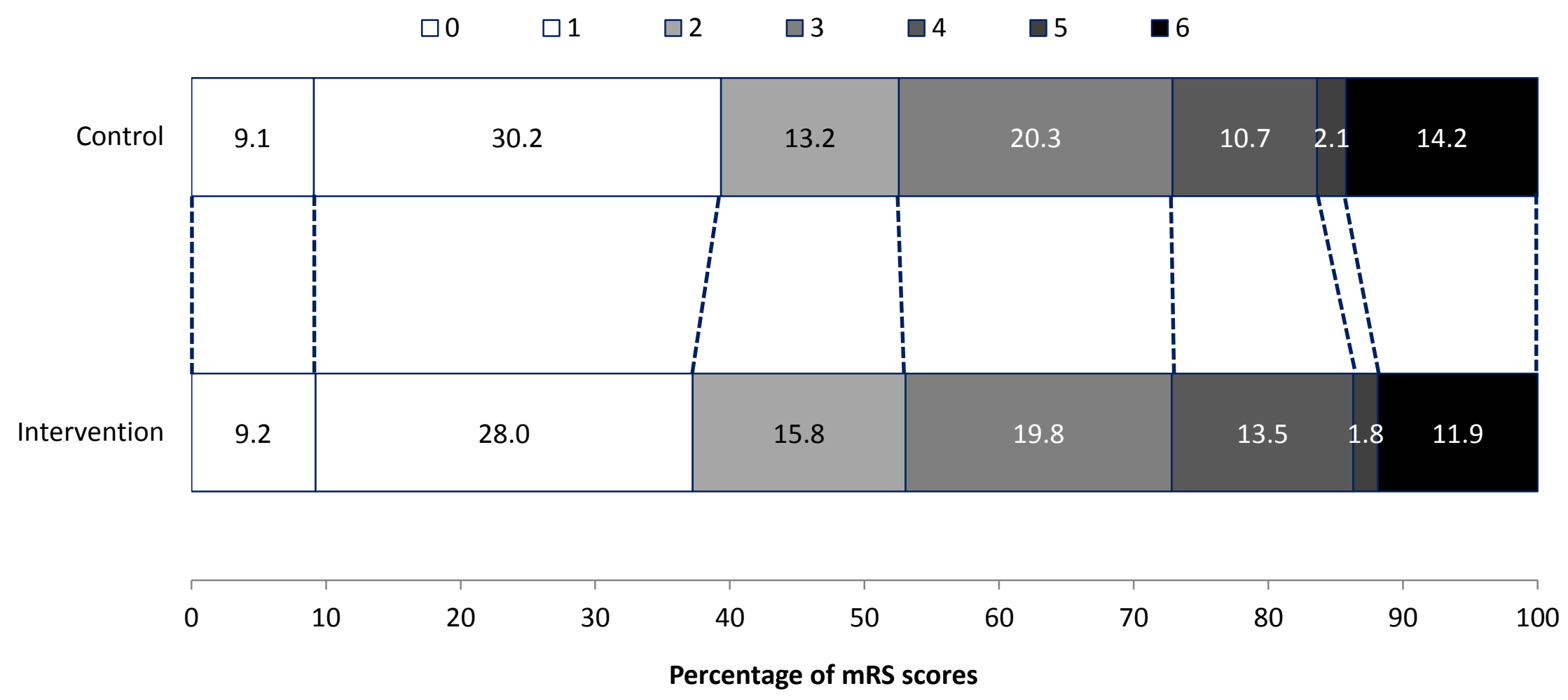


Table 3: Analysis of secondary outcomes at Month 3 and Month 6

\begin{tabular}{|c|c|c|c|c|c|c|}
\hline & \multicolumn{3}{|c|}{ Month 3} & \multicolumn{3}{|c|}{ Month 6} \\
\hline & Intervention & Control & P-value & Intervention & Control & P-value \\
\hline Complete recovery from stroke & $72 / 546(13 \cdot 2)$ & $78 / 530(14 \cdot 7)$ & $0.55^{*}$ & $133 / 534(24 \cdot 9)$ & $142 / 514(27 \cdot 6)$ & $0 \cdot 28^{*}$ \\
\hline Need help for everyday activities & $332 / 543(61 \cdot 1)$ & $320 / 528(60 \cdot 6)$ & $0 \cdot 60^{*}$ & $266 / 533(49 \cdot 9)$ & $245 / 514(47 \cdot 7)$ & $0 \cdot 17^{*}$ \\
\hline Place of residence & & & $0 \cdot 81 \dagger$ & & & $0.92 \dagger$ \\
\hline Same as before stroke & $516 / 543(95 \cdot 0)$ & $500 / 528(94 \cdot 7)$ & & $502 / 533(94 \cdot 2)$ & $483 / 512(94 \cdot 3)$ & \\
\hline Other & $27 / 543(5 \cdot 0)$ & $28 / 528(5 \cdot 3)$ & & $31 / 533(5 \cdot 8)$ & $29 / 512(5 \cdot 7)$ & \\
\hline In another hospital since admission for stroke & $1 / 27(3 \cdot 7)$ & $1 / 28(3 \cdot 6)$ & & $1 / 31(3 \cdot 2)$ & $0 / 29(0 \cdot 0)$ & \\
\hline In family/ friends` home & $17 / 27(63 \cdot 0)$ & $14 / 28(50 \cdot 0)$ & & $16 / 31(51 \cdot 6)$ & $11 / 29(37 \cdot 9)$ & \\
\hline In same hospital since admission for stroke & & & & $0 / 31(0 \cdot 0)$ & $1 / 29(3 \cdot 4)$ & \\
\hline Other dwelling place & $9 / 27(33 \cdot 3)$ & $13 / 28(46 \cdot 4)$ & & $14 / 31(45 \cdot 2)$ & $17 / 29(58 \cdot 6)$ & \\
\hline
\end{tabular}

Barthel Index total score

$0 \cdot 41 \ddagger$

$0 \cdot 74 \ddagger$

$\mathrm{N}$ Mean (SD)

Median (interquartile range)

$\min \max$

\section{$543 \quad 76 \cdot 1(25 \cdot 24) \quad 525 \quad 74 \cdot 8(26 \cdot 05)$}

85 (60 to100)

0100

$85(60$ to 100$)$

0100
$533 \quad 82 \cdot 1(23 \cdot 09) \quad 512 \quad 82 \cdot 6(23 \cdot 19)$

95 (70 to 100$) \quad 95$ (70 to 100$)$ 


\begin{tabular}{|c|c|c|c|c|c|c|}
\hline \multirow[b]{2}{*}{ Caregiver burden total score } & \multicolumn{3}{|c|}{ Month 3} & \multicolumn{3}{|c|}{ Month 6} \\
\hline & & & $0 \cdot 21 \ddagger$ & & & $0.52 \ddagger$ \\
\hline $\mathrm{N}$ Mean (SD) & $54330 \cdot 9(10 \cdot 70)$ & $524 \quad 31 \cdot 7(11 \cdot 38)$ & & $53228 \cdot 9(10 \cdot 01)$ & $51129 \cdot 3(10 \cdot 85)$ & \\
\hline Median (interquartile range) & 27 (22 to 35$)$ & 29 (22 to 37$)$ & & 2521 to 33 & 25 (21 to 33$)$ & \\
\hline $\min \max$ & 2173 & 2180 & & 2177 & 2181 & \\
\hline \multicolumn{7}{|l|}{ Nottingham Extended ADL Scale } \\
\hline Total score & & & $0.43 \dagger$ & & & $0 \cdot 86 \dagger$ \\
\hline $\mathrm{N}$ Mean (SD) & $53727 \cdot 1(17 \cdot 21)$ & $52326 \cdot 3(17 \cdot 31)$ & & $52731 \cdot 0(17 \cdot 67)$ & $50931 \cdot 2(17 \cdot 52)$ & \\
\hline Median (interquartile range) & 27 (12 to 40$)$ & 25 (11 to 40$)$ & & 31 (16 to 45$)$ & 32 (17 to 44$)$ & \\
\hline $\min \max$ & 066 & 066 & & 066 & 066 & \\
\hline \multicolumn{7}{|l|}{ WHOQOL-BREF } \\
\hline Physical health & & & $0.96 \ddagger$ & & & $0.63 \ddagger$ \\
\hline $\mathrm{N}$ Mean (SD) & $53451 \cdot 2(12 \cdot 65)$ & $52151 \cdot 3(12 \cdot 28)$ & & $52554 \cdot 3(12 \cdot 06)$ & $50954 \cdot 7(12 \cdot 11)$ & \\
\hline Median (interquartile range) & 56 (44 to 63$)$ & 56 (44 to 63$)$ & & 56 (44 to 63$)$ & 56 (44 to 63$)$ & \\
\hline $\min \max$ & 1381 & 681 & & 1394 & 19100 & \\
\hline Psychological & & & $0.99 \ddagger$ & & & $0 \cdot 17 \ddagger$ \\
\hline $\mathrm{N}$ Mean (SD) & $534 \quad 49 \cdot 2(15 \cdot 16)$ & $52149 \cdot 3(14 \cdot 99)$ & & $52552 \cdot 1(15 \cdot 09)$ & $50953 \cdot 4(14 \cdot 63)$ & \\
\hline Median (interquartile range) & 5038 to 56$)$ & 50 (38 to 63) & & 56 (44 to 63 ) & 56 (44 to 63 ) & \\
\hline $\min \max$ & 6100 & 694 & & 094 & 688 & \\
\hline Social relationship & & & $0.42 \ddagger$ & & & $0.45 \ddagger$ \\
\hline
\end{tabular}




\begin{tabular}{|c|c|c|c|c|c|c|}
\hline & & Month 3 & & & Month 6 & \\
\hline $\mathrm{N}$ Mean (SD) & $52960 \cdot 8(17 \cdot 21)$ & $51960 \cdot 0(16 \cdot 89)$ & & $52363 \cdot 0(17 \cdot 41)$ & $509 \quad 62 \cdot 2(18 \cdot 43)$ & \\
\hline Median (interquartile range) & 69 (50 to 75$)$ & 56 (50 to 69$)$ & & 69 (50 to 75$)$ & 69 (50 to 75$)$ & \\
\hline $\min \max$ & 0100 & 0100 & & 0100 & 0100 & \\
\hline Environment & & & $0 \cdot 61 \ddagger$ & & & $0 \cdot 76 \ddagger$ \\
\hline $\mathrm{N}$ Mean (SD) & $53465 \cdot 3(14 \cdot 70)$ & $52164 \cdot 8(15 \cdot 78)$ & & $525 \quad 67 \cdot 8(15 \cdot 69)$ & $50968 \cdot 1(15 \cdot 95)$ & \\
\hline Median (interquartile range) & 69 (56 to 75$)$ & 63 (56 to 75$)$ & & 69 (56 to 75$)$ & 69 (56 to 81) & \\
\hline $\min \max$ & 19100 & 13100 & & 19100 & 19100 & \\
\hline Quality of life & & & $0 \cdot 41^{*}$ & & & $0.52^{*}$ \\
\hline Very poor & $21 / 535(3 \cdot 9)$ & $34 / 521(6 \cdot 5)$ & & $17 / 526(3 \cdot 2)$ & $17 / 509(3 \cdot 3)$ & \\
\hline Poor & $97 / 535(18 \cdot 1)$ & $86 / 521(16 \cdot 5)$ & & $77 / 526(14 \cdot 6)$ & $72 / 509(14 \cdot 1)$ & \\
\hline Neither poor nor good & $176 / 535(32 \cdot 9)$ & $167 / 521(32 \cdot 1)$ & & $115 / 526(21 \cdot 9)$ & $105 / 509(20 \cdot 6)$ & \\
\hline Good & $225 / 535(42 \cdot 1)$ & $217 / 521(41 \cdot 7)$ & & $284 / 526(54 \cdot 0)$ & $268 / 509(52 \cdot 7)$ & \\
\hline Very good & $16 / 535(3 \cdot 0)$ & $17 / 521(3 \cdot 3)$ & & $33 / 526(6 \cdot 3)$ & $47 / 509(9 \cdot 2)$ & \\
\hline Satisfaction with health & & & $0 \cdot 31^{*}$ & & & $0.65^{*}$ \\
\hline Very dissatisfied & $24 / 535(4 \cdot 5)$ & $17 / 521(3 \cdot 3)$ & & $18 / 526(3 \cdot 4)$ & $16 / 509(3 \cdot 1)$ & \\
\hline Dissatisfied & $142 / 535(26 \cdot 5)$ & $123 / 521(23 \cdot 6)$ & & $111 / 526(21 \cdot 1)$ & $92 / 509(18 \cdot 1)$ & \\
\hline Neither satisfied nor dissatisfied & $152 / 535(28 \cdot 4)$ & $156 / 521(29 \cdot 9)$ & & $105 / 526(20 \cdot 0)$ & $104 / 509(20 \cdot 4)$ & \\
\hline Satisfied & $204 / 535(38 \cdot 1)$ & $203 / 521(39 \cdot 0)$ & & $257 / 526(48 \cdot 9)$ & $254 / 509(49 \cdot 9)$ & \\
\hline Very satisfied & $13 / 535(2 \cdot 4)$ & $22 / 521(4 \cdot 2)$ & & $35 / 526(6 \cdot 7)$ & $43 / 509(8 \cdot 4)$ & \\
\hline \multicolumn{7}{|l|}{ EQ-5D } \\
\hline
\end{tabular}




\begin{tabular}{|c|c|c|c|c|c|c|}
\hline \multirow[b]{2}{*}{ Mobility } & \multicolumn{3}{|c|}{ Month 3} & \multicolumn{3}{|c|}{ Month 6} \\
\hline & & & $0 \cdot 37^{*}$ & & & $0 \cdot 32^{*}$ \\
\hline I have no problems in walking & $256 / 539(47 \cdot 5)$ & $226 / 523(43 \cdot 2)$ & & $292 / 529(55 \cdot 2)$ & $282 / 510(55 \cdot 3)$ & \\
\hline I have some problems in walking & $235 / 539(43 \cdot 6)$ & $247 / 523(47 \cdot 2)$ & & $201 / 529(38 \cdot 0)$ & $204 / 510(40 \cdot 0)$ & \\
\hline I am confined to bed & $48 / 539(8 \cdot 9)$ & $50 / 523(9 \cdot 6)$ & & $36 / 529(6 \cdot 8)$ & $24 / 510(4 \cdot 7)$ & \\
\hline Self-care & & & $0.52^{*}$ & & & $0 \cdot 75^{*}$ \\
\hline I have no problems with self-care & $235 / 539(43 \cdot 6)$ & $212 / 523(40 \cdot 5)$ & & $278 / 529(52 \cdot 6)$ & $280 / 510(54 \cdot 9)$ & \\
\hline I have some problems bathing or dressing myself & 199/539 (36·9) & $197 / 523(37 \cdot 7)$ & & $176 / 529(33 \cdot 3)$ & $162 / 510(31 \cdot 8)$ & \\
\hline I am unable to bathe or dress myself & $105 / 539(19 \cdot 5)$ & $114 / 523(21 \cdot 8)$ & & $75 / 529(14 \cdot 2)$ & $68 / 510(13 \cdot 3)$ & \\
\hline Usual activities & & & $0.95^{*}$ & & & $0.59^{*}$ \\
\hline I have no problems in performing my usual activities & $185 / 538(34 \cdot 4)$ & $175 / 523(33 \cdot 5)$ & & $227 / 529(42 \cdot 9)$ & $232 / 510(45 \cdot 5)$ & \\
\hline I have some problems in performing my usual activities & $210 / 538(39 \cdot 0)$ & $206 / 523(39 \cdot 4)$ & & $211 / 529(39 \cdot 9)$ & $188 / 510(36 \cdot 9)$ & \\
\hline I am unable to perform my usual activities & $143 / 538(26 \cdot 6)$ & $142 / 523(27 \cdot 2)$ & & $91 / 529(17 \cdot 2)$ & $90 / 510(17 \cdot 6)$ & \\
\hline Pain/discomfort & & & $0 \cdot 70^{*}$ & & & $0 \cdot 64^{*}$ \\
\hline I have no pain or discomfort & $228 / 538(42 \cdot 4)$ & $210 / 523(40 \cdot 2)$ & & $270 / 529(51 \cdot 0)$ & $273 / 510(53 \cdot 5)$ & \\
\hline I have moderate pain or discomfort & $270 / 538(50 \cdot 2)$ & $269 / 523(51 \cdot 4)$ & & $231 / 529(43 \cdot 7)$ & $208 / 510(40 \cdot 8)$ & \\
\hline I have extreme pain or discomfort & $40 / 538(7 \cdot 4)$ & $44 / 523(8 \cdot 4)$ & & $28 / 529(5 \cdot 3)$ & $29 / 510(5 \cdot 7)$ & \\
\hline Anxiety/Depression & & & $0 \cdot 70^{*}$ & & & $0 \cdot 44^{*}$ \\
\hline I am not anxious or depressed & $229 / 538(42 \cdot 6)$ & $212 / 523(40 \cdot 5)$ & & $265 / 529(50 \cdot 1)$ & $257 / 510(50 \cdot 4)$ & \\
\hline I am moderately anxious or depressed & $266 / 538(49 \cdot 4)$ & $272 / 523(52 \cdot 0)$ & & $238 / 529(45 \cdot 0)$ & $219 / 510(42 \cdot 9)$ & \\
\hline I am extremely anxious or depressed & $43 / 538(8 \cdot 0)$ & $39 / 523(7 \cdot 5)$ & & $26 / 529(4 \cdot 9)$ & $34 / 510(6 \cdot 7)$ & \\
\hline
\end{tabular}




\begin{tabular}{|c|c|c|c|c|c|c|}
\hline \multirow[b]{2}{*}{ Overall health state } & \multicolumn{3}{|c|}{ Month 3} & \multicolumn{3}{|c|}{ Month 6} \\
\hline & & & $0 \cdot 68 \ddagger$ & & & $0 \cdot 18 \ddagger$ \\
\hline $\mathrm{N}$ Mean (SD) & $53963 \cdot 2(21 \cdot 21)$ & $52363 \cdot 8(20 \cdot 82)$ & & $52970 \cdot 1(20 \cdot 36)$ & $51071 \cdot 8(20 \cdot 40)$ & \\
\hline Median (interquartile range) & 65 (50 to 80$)$ & 65 (50 to 80$)$ & & 70 (55 to 90$)$ & 75 (60 to 90$)$ & \\
\hline $\min \max$ & 3100 & 0100 & & 0100 & 0100 & \\
\hline \multicolumn{7}{|c|}{ Hospital Anxiety and Depression Scale } \\
\hline \multicolumn{7}{|l|}{ Patient } \\
\hline HADS Total score & & & $0 \cdot 67 \ddagger$ & & & $0.90 \ddagger$ \\
\hline $\mathrm{N}$ Mean (SD) & $536 \quad 11 \cdot 3(8 \cdot 35)$ & $52011.5(8 \cdot 72)$ & & $5279 \cdot 0(7 \cdot 81)$ & $5099 \cdot 1(8 \cdot 64)$ & \\
\hline Median (interquartile range) & 10 (5 to 17$)$ & $10(4$ to 18$)$ & & 7 (3 to 14$)$ & 7 (2 to 13$)$ & \\
\hline $\min \max$ & 039 & 039 & & 038 & 042 & \\
\hline HADS Anxiety score & & & $0.57 \ddagger$ & & & $0.91 \ddagger$ \\
\hline $\mathrm{N}$ Mean (SD) & $536 \quad 4 \cdot 8(4 \cdot 01)$ & $520 \quad 4 \cdot 9(4 \cdot 36)$ & & $527 \quad 3 \cdot 7(3 \cdot 74)$ & $5093 \cdot 7(4 \cdot 19)$ & \\
\hline Median (interquartile range) & 4 (1 to 7$)$ & 4 (1 to 8$)$ & & $3(0$ to 6$)$ & $2(0$ to 6$)$ & \\
\hline $\min \max$ & 018 & 018 & & 018 & 021 & \\
\hline Score $>=8$ & $122 / 536(22 \cdot 8)$ & $138 / 520(26 \cdot 5)$ & $0 \cdot 15^{*}$ & $84 / 527(15 \cdot 9)$ & $83 / 509(16 \cdot 3)$ & $0 \cdot 87^{*}$ \\
\hline HADS Depression score & & & $0 \cdot 79 \ddagger$ & & & $0.91 \ddagger$ \\
\hline $\mathrm{N}$ Mean (SD) & $536 \quad 6 \cdot 5(4 \cdot 94)$ & $5206 \cdot 6(4 \cdot 99)$ & & $527 \quad 5 \cdot 3(4 \cdot 64)$ & $5095 \cdot 3(4 \cdot 96)$ & \\
\hline Median (interquartile range) & $6(2$ to 10$)$ & $6(2$ to 10$)$ & & 4 (2 to 8$)$ & 4 (1 to 8$)$ & \\
\hline $\min \max$ & 021 & 021 & & 021 & 021 & \\
\hline Score $>=8$ & $197 / 536(36 \cdot 8)$ & $198 / 520(38 \cdot 1)$ & $0.66^{*}$ & $145 / 527(27 \cdot 5)$ & $141 / 509(27 \cdot 7)$ & $0.95^{*}$ \\
\hline
\end{tabular}




\begin{tabular}{|c|c|c|c|c|c|c|}
\hline \multirow[b]{2}{*}{ Caregiver } & \multicolumn{3}{|c|}{ Month 3} & \multicolumn{3}{|c|}{ Month 6} \\
\hline & & & & & & \\
\hline HADS Total score & & & $0.62 \ddagger$ & & & $0 \cdot 86 \ddagger$ \\
\hline $\mathrm{N}$ Mean (SD) & $546 \quad 7 \cdot 5(7 \cdot 52)$ & $527 \quad 7 \cdot 7(7 \cdot 88)$ & & $5325 \cdot 5(6 \cdot 68)$ & $5115 \cdot 5(6 \cdot 80)$ & \\
\hline Median (interquartile range) & 5 (2 to 12$)$ & 5 (1 to 12$)$ & & $3(0$ to 9$)$ & $3(0$ to 8$)$ & \\
\hline $\min \max$ & 042 & $0 \quad 39$ & & 036 & 042 & \\
\hline HADS Anxiety score & & & $0.67 \ddagger$ & & & $0.91 \ddagger$ \\
\hline $\mathrm{N}$ Mean (SD) & $546 \quad 3 \cdot 7(3 \cdot 86)$ & $527 \quad 3 \cdot 8(4 \cdot 17)$ & & $532 \quad 2 \cdot 7(3 \cdot 40)$ & $5112 \cdot 6(3 \cdot 51)$ & \\
\hline Median (interquartile range) & $2(0$ to 6$)$ & $2(0$ to 6$)$ & & $1(0$ to 4$)$ & $1(0$ to 4$)$ & \\
\hline $\min \max$ & $0 \quad 21$ & 020 & & 016 & 021 & \\
\hline Score $>=8$ & $83 / 546(15 \cdot 2)$ & $96 / 527(18 \cdot 2)$ & $0 \cdot 19^{*}$ & $55 / 532(10 \cdot 3)$ & $50 / 511(9 \cdot 8)$ & $0 \cdot 77^{*}$ \\
\hline HADS Depression score & & & $0 \cdot 61 \ddagger$ & & & $0.82 \ddagger$ \\
\hline $\mathrm{N}$ Mean (SD) & $546 \quad 3 \cdot 8(4 \cdot 17)$ & $527 \quad 3 \cdot 9(4 \cdot 16)$ & & $5322 \cdot 9(3.69)$ & $5112 \cdot 8(3 \cdot 60)$ & \\
\hline Median (interquartile range) & $3(0$ to 6$)$ & $3(0$ to 6$)$ & & $1(0$ to 5$)$ & $2(0$ to 5$)$ & \\
\hline $\min \max$ & 021 & 021 & & 021 & 021 & \\
\hline Score $>=8$ & $100 / 546(18 \cdot 3)$ & $100 / 527(19 \cdot 0)$ & $0 \cdot 78^{*}$ & $68 / 532(12 \cdot 8)$ & $56 / 511(11 \cdot 0)$ & $0 \cdot 36^{*}$ \\
\hline
\end{tabular}


Figure 3

\begin{tabular}{|c|c|c|c|c|c|c|}
\hline & Intervention & Control & $\begin{array}{r}\text { Favors } \\
\text { Intervention }\end{array}$ & \begin{tabular}{|l} 
Favors \\
Control
\end{tabular} & Odds Ratio (95\% Cl) & $\begin{array}{l}\text { P value for } \\
\text { Interaction }\end{array}$ \\
\hline \multicolumn{7}{|l|}{ Age (years) } \\
\hline 0 to $<40$ & $11 / 56(19 \cdot 6 \%)$ & $18 / 56(32 \cdot 1 \%)$ & & & $0.52(0.22-1.23)$ & 0.23 \\
\hline 40 to $<50$ & $34 / 87(39 \cdot 1 \%)$ & $36 / 96$ (37.5\%) & & & $1.07(0.59-1.94)$ & \\
\hline 50 to $<60$ & $72 / 186(38 \cdot 7 \%)$ & 69/ $154(44 \cdot 8 \%)$ & $\longrightarrow$ & & $0.78(0.50-1.20)$ & \\
\hline 60 to $<70$ & $95 / 168(56 \cdot 5 \%)$ & $86 / 171(50 \cdot 3 \%)$ & & & $1.29(0.84-1.97)$ & \\
\hline 70 or more & $73 / 110(66 \cdot 4 \%)$ & $78 / 128$ (60.9\%) & & 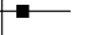 & $1.26(0.74-2.15)$ & \\
\hline \multicolumn{7}{|l|}{ Sex } \\
\hline Female & $115 / 198(58 \cdot 1 \%)$ & $102 / 204(50 \cdot 0 \%)$ & & & $1.39(0.93-2.05)$ & 0.04 \\
\hline Male & $170 / 409(41 \cdot 6 \%)$ & )185/ $401(46 \cdot 1 \%)$ & & & $0.83(0.63-1.10)$ & \\
\hline \multicolumn{7}{|l|}{ Stroke severity (NIHSS)* } \\
\hline $0-<5$ & $18 / 71(25 \cdot 4 \%)$ & 15/ 98 (15·3\%) & & & $1.88(0.87-4.05)$ & 0.14 \\
\hline $5-<10$ & $84 / 242(34 \cdot 7 \%)$ & $85 / 237$ (35.9\%) & & & $0.95(0.65-1.38)$ & \\
\hline $10-<15$ & $101 / 185(54 \cdot 6 \%)$ & $106 / 173(61 \cdot 3 \%)$ & & & $0.76(0.50-1.16)$ & \\
\hline$>=15$ & $82 / 109(75 \cdot 2 \%)$ & $81 / 97(83 \cdot 5 \%)$ & $=$ & - & $0.60(0.30-1.20)$ & \\
\hline \multicolumn{7}{|l|}{ Stroke type } \\
\hline Intracerebral heamorrhage & $69 / 139(49 \cdot 6 \%)$ & $78 / 142(54 \cdot 9 \%)$ & & & $0.81(0.51-1.29)$ & 0.35 \\
\hline Ischaemic & $216 / 467(46 \cdot 3 \%)$ & ) $209 / 462(45 \cdot 2 \%)$ & & & $1.04(0.80-1.35)$ & \\
\hline \multicolumn{7}{|l|}{ OCSP subtype † } \\
\hline Lacunar syndromes & $22 / 76(28 \cdot 9 \%)$ & $19 / 79(24 \cdot 1 \%)$ & & & $1.29(0.63-2.63)$ & 0.51 \\
\hline Partial anterior circulation syndrome & $126 / 253(49 \cdot 8 \%)$ & $124 / 260(47 \cdot 7 \%)$ & & & $1.09(0.77-1.54)$ & \\
\hline Posterior circulation syndrome & $29 / 71(40 \cdot 8 \%)$ & $37 / 72(51 \cdot 4 \%)$ & & & $0.65(0.34-1.27)$ & \\
\hline Total anterior circulation syndrome & $39 / 67(58 \cdot 2 \%)$ & $28 / 50(56 \cdot 0 \%)$ & & & $1.09(0.52-2.29)$ & \\
\hline \multicolumn{7}{|l|}{ Caregiver type } \\
\hline Daughter or Daughter in law & $89 / 148(60 \cdot 1 \%)$ & $65 / 123(52 \cdot 8 \%)$ & & & $1.35(0.83-2.18)$ & 0.43 \\
\hline Son or Son in law & $84 / 166(50 \cdot 6 \%)$ & $102 / 184(55 \cdot 4 \%)$ & & & $0.82(0.54-1.25)$ & \\
\hline Spouse & $97 / 252(38.5 \%)$ & $105 / 253(41 \cdot 5 \%)$ & & & $0.88(0.62-1.26)$ & \\
\hline Other & 15/ $41(36 \cdot 6 \%)$ & $15 / 45(33 \cdot 3 \%)$ & & & $1.15(0.47-2.80)$ & \\
\hline \multicolumn{7}{|l|}{ Education level $\ddagger$} \\
\hline College/university Postgraduate & $66 / 165(40 \cdot 0 \%)$ & $58 / 154(37 \cdot 7 \%)$ & & & $1 \cdot 10(0 \cdot 70-1 \cdot 73)$ & $0 \cdot 17$ \\
\hline High school completed & $50 / 123(40 \cdot 7 \%)$ & $73 / 137(53 \cdot 3 \%)$ & & & $0.60(0.37-0.98)$ & \\
\hline Primary/Secondary/Less than primary & $1114 / 231(49 \cdot 4 \%)$ & $104 / 223(46 \cdot 6 \%)$ & & & $1.11(0.77-1.61)$ & \\
\hline No schooling & $54 / 87(62 \cdot 1 \%)$ & $52 / 91(57 \cdot 1 \%)$ & & & $1.23(0.67-2.24)$ & \\
\hline \multicolumn{7}{|l|}{ Household income $\S$} \\
\hline$<5000$ & $57 / 93(61 \cdot 3 \%)$ & $53 / 97(54 \cdot 6 \%)$ & & $=$ & $1.31(0.74-2.34)$ & 0.48 \\
\hline $5000-14999$ & $72 / 173(41 \cdot 6 \%)$ & $94 / 190(49 \cdot 5 \%)$ & & & $0.73(0.48-1.10)$ & \\
\hline 15000-29999 & $69 / 163(42 \cdot 3 \%)$ & $59 / 146(40 \cdot 4 \%)$ & & 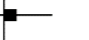 & $1.08(0.69-1.70)$ & \\
\hline 30000 and more & $55 / 121(45 \cdot 5 \%)$ & $44 / 103(42 \cdot 7 \%)$ & & & $1.12(0.66-1.90)$ & \\
\hline NO answer or missing & $32 / 57(56 \cdot 1 \%)$ & $37 / 69(53 \cdot 6 \%)$ & & & $1.11(0.55-2 \cdot 24)$ & \\
\hline \multicolumn{7}{|l|}{ Type of accommodation } \\
\hline Own house & $234 / 489(47 \cdot 9 \%)$ & $233 / 482(48 \cdot 3 \%)$ & & - & $0.98(0.76-1.26)$ & 0.98 \\
\hline \multirow[t]{3}{*}{ Others } & $51 / 118(43 \cdot 2 \%)$ & $54 / 123(43 \cdot 9 \%)$ & $\longrightarrow$ & & $0.97(0.58-1.62)$ & \\
\hline & & 0.2 & & .0 & .0 & \\
\hline & & & & Ratio & & \\
\hline
\end{tabular}




\section{References}

1. Feigin VL, Forouzanfar MH, Krishnamurthi R, et al. Global and regional burden of stroke during 1990-2010: findings from the Global Burden of Disease Study 2010. Lancet 2014;383:245-55.

2. Joshi R, Alim M, Kengne AP, et al. Task Shifting for Non-Communicable Disease Management in Low and Middle Income Countries - A Systematic Review. PLoS ONE 2014;9:e103754.

3. Govindarajan V, Ramamurti R. Delivering World-Class Health Care, Affordably. Harvard Business Review 2013;91:117-22.

4. Organization WH. Task shifting: rational redistribution of tasks among health workforce teams: global recommendations and guidelines. Geneva: WHO; 2008.

5. Langhorne $P$, de Villiers L, Pandian JD. Applicability of stroke-unit care to low-income and middle-income countries. The Lancet Neurology 2012;11:341-8.

6. Kalkonde YV, Deshmukh MD, Sahane V, et al. Stroke Is the Leading Cause of Death in Rural Gadchiroli, India: A Prospective Community-Based Study. Stroke 2015;46:1764-8.

7. Pandian JD, Sudhan P. Stroke Epidemiology and Stroke Care Services in India. J

Stroke 2013;15:128-34.

8. Dieleman JL, Templin T, Sadat N, et al. National spending on health by source for 184 countries between 2013 and 2040. The Lancet 2016;387:2521-35.

9. World Report on Disability: World Health Organisation; 2011.

10. Alim M, Lindley R, Felix C, et al. Family-led rehabilitation after stroke in India: the ATTEND trial, study protocol for a randomized controlled trial. Trials 2016;17:1-8.

11. Pandian JD, Felix C, Kaur P, et al. FAmily-Led RehabiliTaTion aftEr Stroke in INDia: the ATTEND pilot study. International Journal of Stroke 2015;10:609-14.

12. Stroke Unit Trialists Collaboration. Organised inpatient (stroke unit) care for stroke (Cochrane Review). The Cochrane Library. Chichester,UK: John Wiley and Sons; 2003.

13. Early Supported Discharge Trialists. Services for reducing duration of hospital care for acute stroke patients. Oxford: Cochrane Database of Systematic Reviews; 2005.

14. French B, Thomas LH, Leathley MJ, et al. Repetitive task training for improving functional ability after stroke. Cochrane Database of Systematic Reviews 2007.

15. van Swieten JC, Koudstaal PJ, Visser MC, Schouten HJA. Interobserver Agreement for the Assessment of Handicap in Stroke Patients. Stroke 1988;19:604-7.

16. Lindley RI, Waddell F, Livingstone $\mathrm{M}$, et al. Can simple questions assess outcome after stroke? Cerebrovascular Diseases 1994;4:314-24.

17. Mahoney FI, Barthel DW. Functional Evaluation: The Barthel Index. A simple index of independence useful in scoring improvement in the rehabilitation of the chronically ill.

Maryland State Medical Journal 1965;14:61-5.

18. Nouri FM, Lincoln NB. An extended activities of daily living scale for stroke patients.

Clin Rehabil 1987;1:301-5.

19. Anonymous. Development of the World Health Organization WHOQOL-BREF quality of life assessment. The WHOQOL Group. Psychological Medicine;28:551-8.

20. EuroQol G. EuroQol--a new facility for the measurement of health-related quality of life. Health Policy 1990;16:199-208.

21. Zigmond AS, Snaith RP. The hospital anxiety and depression scale. Acta psychiatr scand 1983;67:361-70. 
22. Elmstahl S MB, Annerstedt L. Caregiver's Burden of Patients 3 Years After Stroke Assessed by a Novel Caregiver Burden Scale. Arch Phys Med Rehabil 1996;77:177-82.

23. Billot L, Lindley RI, Harvey LA, et al. Statistical analysis plan for the family-led rehabilitation after stroke in India (ATTEND) trial: A multicenter randomized controlled trial of a new model of stroke rehabilitation compared to usual care. International Journal of Stroke 2017;12:208-10.

24. Howard G, Waller JL, Voeks JH, et al. A simple, assumption-free, and clinically interpretable approach for analysis of modified Rankin outcomes. Stroke 2012;43:664-9.

25. Billot L, Lindley RI, Harvey LA, et al. Statistical analysis plan for the family-led rehabilitation after stroke in India (ATTEND) trial: a multicentre randomised controlled trial of a new model of stroke rehabilitation compared to usual care International Journal of Stroke In press.

26. Vloothuis JDM, Mulder M, Veerbeek JM, et al. Caregiver-mediated exercises for improving outcomes after stroke. Cochrane Database of Systematic Reviews 2016.

27. Party ISW. National clinical guideline for stroke. 4th Edition ed. London2012.

28. Hassett $\mathrm{L}$, van den Berg M, Lindley RI, et al. Effect of affordable technology on physical activity levels and mobility outcomes in rehabilitation: a protocol for the Activity and MObility UsiNg Technology (AMOUNT) rehabilitation trial. BMJ Open 2016;6:e012074.

29. Forster A, Dickerson J, Young J, et al. A structured training programme for caregivers of inpatients after stroke (TRACS): a cluster randomised controlled trial and costeffectiveness analysis. Lancet 2013;382:2069-76.

30. Liu $\mathrm{H}$, Lindley $\mathrm{R}$, Alim $\mathrm{M}$, et al. Protocol for process evaluation of a randomised controlled trial of family-led rehabilitation post stroke (ATTEND) in India. BMJ Open 2016;6. 31. Pandian JD, Singh G, Kaur P, et al. Incidence, short-term outcome, and spatial distribution of stroke patients in Ludhiana, India. Neurology 2016;86:425-33.

32. Eaton J, McCay L, Semrau M, et al. Scale up of services for mental health in lowincome and middle-income countries. The Lancet;378:1592-603.

33. Lancet. Scale up services for mental disorders: a call for action. The Lancet 2007;370:1241-52. 